Мальщев Дмитро Валерійович, кандидат медичних наук, завідувач лабораторії імунології та молекулярної біології НДІ ЕКМ НМУ імені О. О. Богомольця; 01601, бульвар Шевченка 13, м. Київ, Україна; dmaltsev@ukr.net; +38 (068) 100-85-95.

ORCID https://orcid.org/0000-0002-6615-3072

\title{
ЗНАЧЕНИЕ ГЕНЕТИЧЕСКИ ДЕТЕРМИНИРОВАННОГО ДЕФИЦИТА ФЕРМЕНТОВ ФОЛАТНОГО ЦИКЛА В ПАТОГЕНЕЗЕ ЗАБОЛЕВАНИЙ АУТИСТИЧЕСКОГО СПЕКТРА
}

\begin{abstract}
Анотація
Мальцев Дмитро Валерійович, кандидат медичних наук, завідувач лабораторії імунології та молекулярної біології НДІ ЕКМ НМУ імені О. О. Богомольцям. Київ, Україна. Значення генетично детермінованого дефіциту ферментів фолатного циклу в патогенезі захворювань аутистичного спектру.

Ключові слова: аутистичний спектр, цикл фолієвої кислоти, первинний імунодефіцит.

Постановка проблеми. Результати мета-аналізу рандомізованих контрольованих клінічних досліджень вказують на асоціацію генетичного дефіциту фолатного циклу і розладів спектру аутизму у дітей.

Аналіз останніх досліджень і публікацій. $Є$ ряд доказів участі імунної системи в патогенезі розладів спектру аутизму, включаючи асоціацію 3 імунодефіцитами і локусами гістосумісності, випадки розвитку аутизму після нейроінфекцій i аутоімунних енцефалітів, аномально високе мікробне навантаження, ефективність імунотерапії.
\end{abstract}


Формулювання мети статті: Мета - вивчити генетичні, біохімічні та імунологічні зміни у дітей з розладами аутистичного спектру, асоційованими 3 генетичним дефіцитом фолатного циклу.

Виклад основного матеріалу. Результати аналізу генетичних тестів вказують, що у більшості дітей досліджуваної групи відзначалося 2-4 варіанти поліморфізму в генах ферментів фолатного циклу (88\% випадків), а співвідношення гомо- і гетерозиготних форм можна представити як 1,2 до 1,0. Аналіз отриманих нами результатів вивчення біомаркерів в досліджуваній групі показав феномен гіпергомоцистеїнемії в $88 \%$ випадків (р $<0,05 ; \mathrm{Z}<\mathrm{Z}_{0,05}$ ), однак відзначалася значна флуктуація рівня сироваткової концентрації гомоцистеїну в залежності від ряду факторів. Результати вивчення імунного статусу показали, що генетичний дефіцит фолатного циклу шляхом гіпергомоцистеїнеміі призводить до розвитку особливої форми первинного імунодефіциту з варіабельним імунологічним фенотипом, але переважним залученням NK- i NKT-клітин (p=0,01), CD8 + цитотоксичних Т-лімфоцитів і мієлопероксидази фагоцитів $(\mathrm{p}=0,05)$, що зумовлюе різке зниження резистентності до внутрішньоклітинних мікроорганізмів, пухлин і схильність до розвитку системного запалення, аутоімунних реакцій, включаючи антимозковий аутоімунітет, i реакцій гіперчутливості уповільненої типу.

Висновки і перспективи подальших досліджень. Діти з розладами спектру аутизму, асоційованими з генетичним дефіцитом фолатного циклу, $\epsilon$ іммуноскомпрометованими особами. Ми пропонуємо особливу форму первинного імунодефіциту, що відзначається в таких випадках, визначати як «імунодефіцит, асоційований з генетичним порушенням фолатного циклу». Ці дані відкривають перспективи обгрунтованої апробації імунотерапії при розладах спектра аутизму, пов'язаних з генетичним дефіцитом ензимів циклу фолієвої кислоти. 


\section{Аннотация}

Мальцев Дмитрий Валерьевич, кандидат медицинских наук, заведующий лабораторией иммунологии и молекулярной биологии НИИ ЭКМ НМУ имени А. А. Богомольца, Киев, Украина. Значение генетически детерминированного дефицита ферментов фолатного цикла в патогенезе заболеваний аутистического спектра.

Ключевые слова: аутистический спектр, цикл фолиевой кислоты, первичный иммунодефицит.

Постановка проблемы. Результаты мета-анализа рандомизированных контролируеых клинических исследований указывают на ассоциацию генетического дефицита фолатного цикла и расстройств спектра аутизма у детей.

Анализ последних исследований и публикаций. Имеется ряд доказательств участия иммунной системы в патогенезе расстройств спектра аутизма, включая ассоциацию с иммунодефицитами и локусами гистосовместимости, случаи развития аутизма после нейроинфекций и аутоиммунных энцефалитов, аномально высокую микробную нагрузку, эффективность иммунотерапии.

Формулировка цели статьи: Цель - изучить генетические, биохимические и иммунологические изменения у детей с расстройствами аутистического спектра, ассоциированными с генетическим дефицитом фолатного цикла.

Изложение основного материала. Результаты анализа генетических тестов указывают, что у большинства детей исследуемой группы отмечалось 2-4 полиморфизма в генах ферментов фолатного цикла (88\% случаев), а соотношение гомо- и гетерозиготных форм можно представить как 1,2 к 1,0. Анализ полученных нами результатов изучения биомаркеров в исследуемой группе показал феномен гипергомоцистеинемии в 88\% случаев ( $<0,05$; $\left.\mathrm{Z}<\mathrm{Z}_{0,05}\right)$, однако отмечалась значительная флуктуация уровня сывороточной концентрации гомоцистеина в зависимости от ряда факторов. Результаты 
изучения иммунного статуса показали, что генетический дефицит фолатного цикла путем гипергомоцистеинемии приводит к развитию особой формы первичного иммунодефицита с вариабельным иммунологическим фенотипом, но преимущественным вовлечением NK- и NKT-клеток $(\mathrm{p}=0,01)$, CD8+ цитотоксических Т-лимфоцитов и миелопероксидазы фагоцитов $(\mathrm{p}=0,05)$, что предопределяет резкое снижение резистентности к внутриклеточным микроорганизмам, опухолям и склонность к развитию системного воспаления, аутоиммунных реакций, включая антимозговой аутоиммунитет, и реакций гиперчувствительности замедленного типа.

Выводы и перспективы дальнейших исследований. Дети с расстройствами спектра аутизма, ассоциированными с генетическим дефицитом фолатного цикла, являются иммуноскомпрометированными лицами. Мы предлагаем особую форму первичного иммунодефицита, отмечающуюся в таких случаях, определять как «иммунодефицит, ассоциированный с генетическим нарушением фолатного цикла». Эти данные открывают перспективы обоснованной апробации иммунотерапии при расстройствах спектра аутизма, связанных с генетическим дефицитом энзимов цикла фолиевой кислоты.

\section{Annotation}

Maltsev DV, Ph.D., Head of the Laboratory of Immunology and Molecular Biology of the Scientific Research Institute of Ecology of the O. Bohomolets NMU. Kyiv, Ukraine. The value of genetically determined deficiency of enzymes in the folate cycle in the pathogenesis of diseases of the autistic spectrum.

Key words: autistic spectrum, folic acid cycle, primary immunodeficiency.

Formulation of the problem. The results of a meta-analysis of randomized controlled clinical studies indicate an association of genetic folate cycle deficiency and autism spectrum disorders in children. 
Analysis of recent research and publications. There is some evidence that the immune system is involved in the pathogenesis of autism spectrum disorders, including an association with immunodeficiencies and histocompatibility loci, cases of autism after neuroinfections and autoimmune encephalitis, anomalously high microbial load, the effectiveness of immunotherapy.

Formulating the purpose of the article. The goal is to study the genetic, biochemical and immunological changes in children with autism spectrum disorders associated with genetic deficiency of the folate cycle.

Presenting main material. The results of the analysis of genetic tests indicate that the majority of children in the study group had 2-4 polymorphisms in the folate cycle enzyme genes ( $88 \%$ of cases), and the ratio of homo-and heterozygous forms can be represented as 1.2 to 1.0. An analysis of the biomarker results we obtained in the studied group showed the phenomenon of hyperhomocysteinemia in $88 \%$ of cases ( $\mathrm{p}<0.05$; $\mathrm{Z}<\mathrm{Z}_{0.05}$ ), however, there was a significant fluctuation in the level of serum homocysteine concentration depending on a number of factors. The results of the study of the immune status showed that the genetic deficiency of the folate cycle through hyperhomocysteinemia leads to the development of a special form of primary immunodeficiency with variable immunological phenotype, but the predominant involvement of NK and NKT cells $(\mathrm{p}=0,01), \mathrm{CD} 8+$ cytotoxic T-lymphocytes and myeloperoxidase of phagocytes $(p=0,05)$, which will cause low resistance to intracellular microorganisms, tumors, and the propensity to develop systemic inflammation, autoimmune reactions, including anti-brain autoimmunity, and delayed type of hypersensitivity.

Conclusions and perspectives of further research. Children with autism spectrum disorders associated with a genetic deficiency in the folate cycle are immunocompromised individuals. We propose a special form of primary immunodeficiency, noted in such cases, to define as "immunodeficiency associated with a genetic disorder of the folate cycle". These data open up prospects for approbation of immunotherapy for autism spectrum disorders associated with a genetic deficiency of folic acid cycle enzymes. 
Ключевые слова: аутистический спектр, цикл фолиевой кислоты, первичный иммунодефицит.

Постановка проблемы. Расстройства психики аутистического спектра встречаются у 1\% современных детей. В основе этой патологии, по данным ряда ученых, в частности Frye R.E. с соавт., лежат генетические нарушения ферментов фолатного цикла и/или патология митохондрий [7]. Результаты последнего мета-анализа рандомизированных контролируемых клинических исследований подтверждают ассоциацию генетически детерминированного дефицита ферментов цикла фолиевой кислоты и развития расстройств спектра аутизма у детей [12].

Анализ последних исследований и публикаций. В качестве причин генетической предрасположенности к развитию аутистического нарушения психики рассматривают полиморфизмы ферментов фолатного цикла [12], однако связь дефицита ферментов фолатного цикла с аутизмом не вполне обоснована, a наличие у ребенка полиморфизмов генов, равно как и гипергомоцистеинемии, не являются достаточным условием для развития у него психических расстройств. Накопленные доказательства позволяют усмотреть недостающее звено патогенеза расстройств аутистического спектра, ассоциированных с первичным фолатным дефицитом, в иммунозависимой патологии, связанной с некоторыми локусами гистосовместимости, подобно ряду аутоиммунных и аллергических синдромов [1, 2, 5]. Позитивный эффект применения иммунотерапии у пациентов с расстройствами аутистического спектра [6] свидетельствует о роли иммунозависимых механизмов в патогенезе этих заболеваний.

Цикл фолиевой кислоты реализуется благодаря деятельности трех ключевых ферментов: метилентетрагидрофолатредуктазы (MTHFR), метионинсинтазы-редуктазы (MTRR) и метионинсинтазы (MTR), и функционирует в неразрывной связи с циклом метионина, в результате которого синтезируется продукт, получивший название гомоцистеин, 
который оказывает токсическое воздействие на эндотелий сосудов, вызывая состояние эндотелиальной дисфункции, а также на нейроны ЦНС, индуцируя синаптический дисбаланс и гибель клеток. При полиморфизмах в генах ферментов фолатного цикла создаются условия для гипергомоцистеинемии аномально повышенной выработки гомоцистеина [4].

На данный момент описаны два полиморфизма в гене MTHFR, связанные с заменой цитозина на тимин в кодоне 677 (677 C>T) и аденина на цитозин в кодоне 1298 (1298 A>C). В генах MTRR и MTR известны полиморфизмы, обусловленные заменой аденина на гуанозин $(\mathrm{A}>\mathrm{G})$. Указанные полиморфизмы бывают в гетеро- и гомозиготном состоянии. Гетерозиготные полиморфизмы обозначаются MTHFR 677 C/T, MTHFR 1298 A/C, MTRR A/G и MTR A/G, а гомозиготные - MTHFR 677 T/T, MTHFR 1298 C/C, MTRR G/G и MTR G/G (табл. 1). У одного человека может обнаруживаться от 1 до 4 полиморфизмов в генах фолатного цикла в различном состоянии. Метаболические нарушения усугубляются по мере накопления генетических поломок. В среднем каждый из полиморфизмов в генах ферментов фолатного цикла содержится в геноме, по крайней мере, $30 \%$ представителей современной человеческой популяции.

Формулировка цели статьи: Цель - изучить генетические, биохимические и иммунологические изменения у детей с расстройствами аутистического спектра, ассоциированными с генетическим дефицитом фолатного цикла.

Изложение основного материала. В проспективном контролируемом одноцентровом исследовании в период между 2010 и 2015 годами принимали участие 78 детей с диагнозом расстройств психики аутистического спектра и/или детского церебрального паралича, из различных регионов Украины, в возрасте от 2 до 10 лет, 47 мальчиков и 31 девочка. Выявление полиморфизмов генов фолатного цикла осуществляли методом полимеразной цепной реакции в трех центрах: Neurological Research Institute (USA), Харьковском генетическом центре и коммерческой лаборатории 
Синево. Контрольную группу составили 34 здоровых ребенка с похожим возрастным и гендерным распределением.

Таблица 1

\section{Разнообразие и клиническое значение полимофизмов генов фолатного}

\section{цикла у людей}

\begin{tabular}{|c|c|c|c|c|}
\hline Ген & $\begin{array}{l}\text { Полимор } \\
\text { физм }\end{array}$ & $\begin{array}{l}\text { Аллель } \\
\text { нейтраль } \\
\text { ный }\end{array}$ & $\begin{array}{l}\text { Аллель } \\
\text { риска }\end{array}$ & $\begin{array}{ll}\text { Проявления } & \text { генотипа } \\
\text { аллелями риска } & \text { c }\end{array}$ \\
\hline \multirow[t]{2}{*}{ MTHFR } & $\begin{array}{l}\text { MTHFR: } \\
677 \text { C }>\text { T }\end{array}$ & $\mathrm{C} / \mathrm{C}$ & $\begin{array}{l}\mathrm{C} / \mathrm{T}, \quad \mathrm{T} / \mathrm{T} \\
\text { Частота - } \\
30-40 \%\end{array}$ & 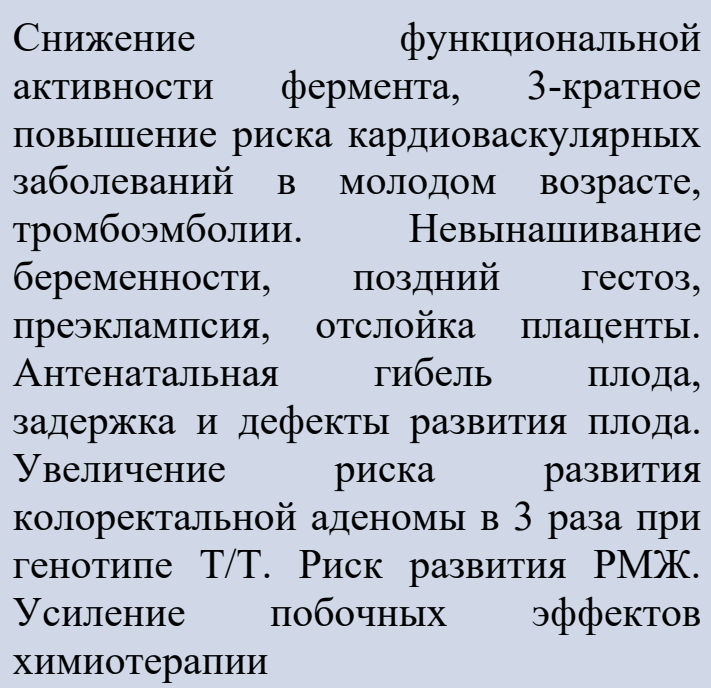 \\
\hline & $\begin{array}{l}\text { MTHFR: } \\
1298 \mathrm{~A}>\mathrm{C}\end{array}$ & $\mathrm{A} / \mathrm{A}$ & $\begin{array}{l}\mathrm{A} / \mathrm{G}, \mathrm{G} / \mathrm{G} \\
\text { Частота - } \\
20-30 \%\end{array}$ & $\begin{array}{l}\text { Снижение } \\
\text { функциональной } \\
\text { активности фермента. Рост уровня } \\
\text { гомоцистеина в крови. Повышение } \\
\text { риска развития синдрома Дауна. } \\
\text { Нарушение развития плода - } \\
\text { незаращение нервной трубки }\end{array}$ \\
\hline MTR & $\begin{array}{l}\text { MTHFR: } \\
1298 \mathrm{~A}>\mathrm{C}\end{array}$ & $\mathrm{A} / \mathrm{A}$ & $\begin{array}{l}\mathrm{A} / \mathrm{G}, \mathrm{G} / \mathrm{G} \\
\text { Частота - } \\
20-30 \%\end{array}$ & $\begin{array}{l}\text { Снижение } \\
\text { функциональной } \\
\text { активности фермента. Рост уровня } \\
\text { гомоцистеина в крови. Повышение } \\
\text { риска развития синдрома Дауна. } \\
\text { Нарушение развития плода - } \\
\text { незаращение нервной трубки }\end{array}$ \\
\hline MTRR & $\begin{array}{l}\text { MTRR: } 66 \\
A>G\end{array}$ & $\mathrm{~A} / \mathrm{A}$ & $\begin{array}{l}\text { A/A, G/G } \\
\text { Частота - } \\
20-30 \%\end{array}$ & \begin{tabular}{l} 
Снижение \\
\multicolumn{2}{c}{ функциональной } \\
активности фермента. Рост уровня \\
гомоцистеина в $\quad$ крови. Дефекты \\
развития нервной трубки. Усиливает \\
патологический \\
ассоциированный с полиморфизмами \\
гена MTHFR
\end{tabular} \\
\hline
\end{tabular}


Всем пациентам проводилось комплексное иммунологическое обследование в Институте иммунологии и аллергологии НМУ имени А.А. Богомольца, которое включало оценку сывороточных концентраций известных биомаркеров генетического дефицита фолатного цикла гомоцистеина, фолиевой кислоты, витаминов В12 и В6.

Статистический анализ полученной информации обработан методами структурного и сравнительного анализов при помощи электронной программы Microsoft Excel. C целью установления достоверности отличий результатов применяли Т-критерий Стьюдента с расчетом коэффициента доверительной вероятности р (параметрический критерий) и число знаков Z по Урбаху (непараметрический критерий). Для изучения связи между полиморфизмами генов фолатного цикла и показателями иммунного статуса использовали критерий хи-квадрат $\left(\chi^{2}\right)$ Пирсона, сравнивая полученное значение с табличным при заданном числе степеней свободы и уровнях достоверности $\mathrm{p}=0,05$ и $\mathrm{p}=0,01$. При фактических значениях от 5 до 9 применяли дополнительно поправку Йейтса, а при менее 5 - точный тест Фишера.

Результаты анализа генетических тестов указывают, что у большинства детей исследуемой группы отмечалось 2-4 полиморфизма в генах ферментов фолатного цикла (88\% случаев), а соотношение гомо- и гетерозиготных форм можно представить как 1,2 к 1,0. Лишь в 12\% случаев наблюдался один полиморфизм, причем преимущественно в гомозиготном состоянии (рис. 1).

У таких детей обычно имела место комбинация с другими генетическими нарушениями, которые влияют на психическое развитие ребенка, а именно - с синдромами Лея (1 случай), Ретта (1 случай) и Дауна (1 случай), а также - гемохроматозом (1 случай) и мутациями гена синтазы оксида азота (2 случая). В целом преобладали замены нуклеотидов в гене MTHFR (56\% случаев), однако тесной ассоциации с каким либо одним генетическим нарушением не отмечалось. 


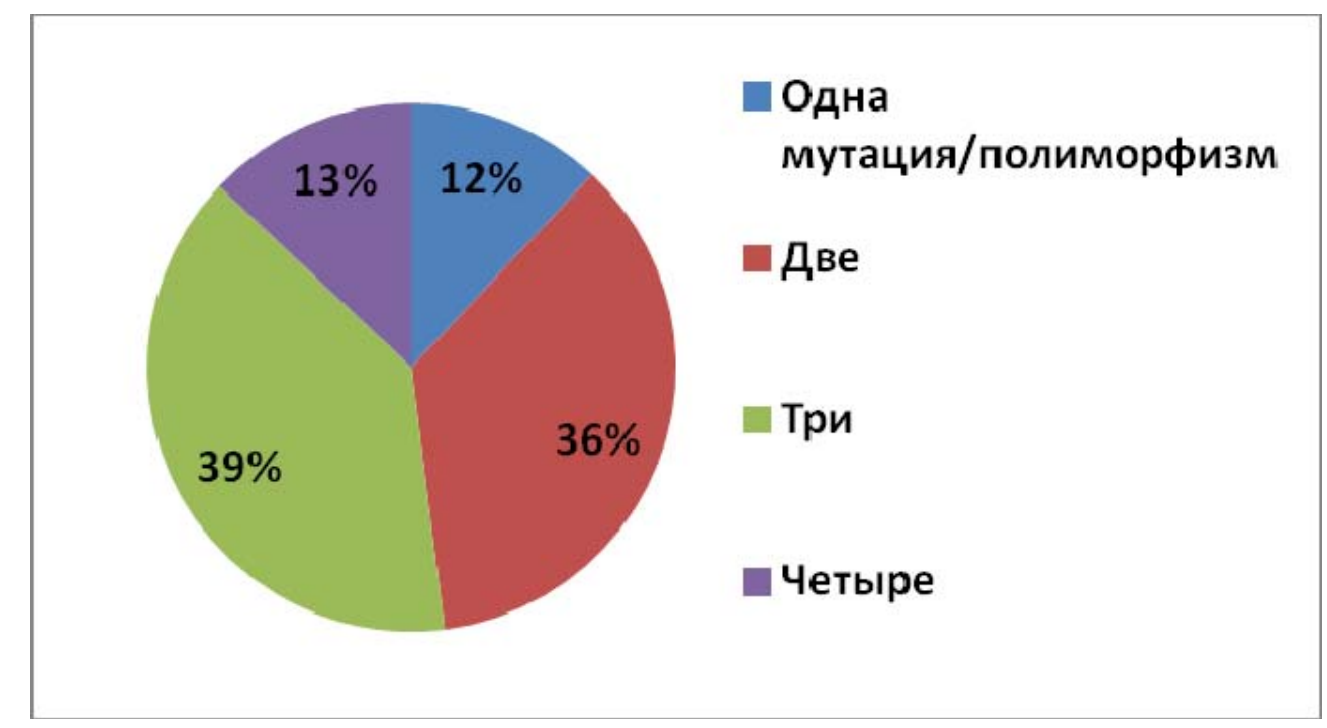

Рис. 1. Структура исследуемой группы $(\mathrm{n}=78)$ по количеству полиморфизмов генов ферментов фолатного цикла

Schoendorfer N.C. с соавторами выявили нарушения процессов метилирования у детей с картиной тяжелого детского церебрального паралича, проявлявшиеся повышением сывороточной концентрации гомоцистеина и метилмалоновой кислоты и снижением содержания уратов по сравнению со здоровыми детьми [16]. Анализ полученных нами результатов изучения биомаркеров в исследуемой группе показал феномен гипергомоцистеинемии в $88 \%$ случаев ( $\left.<<0,05 ; \mathrm{Z}<\mathrm{Z}_{0,05}\right)$, однако отмечалась значительная флуктуация уровня сывороточной концентрации гомоцистеина, в том числе в зависимости от особенностей диеты ребенка, поэтому для получения достоверных результатов нами были проведены серийные исследования на протяжении нескольких недель. Сывороточная концентрация фолиевой кислоты оказалась повышенной в $64 \%$, а пониженной - в 21\% случаев. Повышение содержания витамина В12 также имело место в $64 \%$, а витамина В6 - лишь в $43 \%$ случаев. Гипергомоцистеинемия оказалась наиболее чувствительным биохимическим маркером генетически детерминированного нарушения фолатного цикла (рис. 2), однако в некоторых случаях нормальное содержание гомоцистеина не исключало наличие нескольких полиморфизмов в генах фолатного цикла. 
В результате оценки иммунного статуса установлено, что почти все дети с генетическим дефицитом фолатного цикла были иммуноскомпрометированными лицами, причем отмечались некоторые однотипные нарушения иммунитета. Основой выявленного иммунодефицита было резко сниженное количество клеток субпопуляций лимфоцитов с фенотипом CD3-CD16+CD56+, получившие название естественных киллеров (natural killers, NK), и фенотипом CD3+CD16+CD56+, или естественных киллерных Т-клеток (natural killer T-cell, NKT) в периферической крови. Дефицит NK- и NKT-клеток ассоциирован, в частности, с повышенной склонностью к развитию аутоиммунных осложнений [15] и гиперчувствительности замедленного типа [8], что согласуется с неоднократно зафиксированным феноменом аномально повышенной продукции аутоантител к мозговым антигенам и непереносимости многих пищевых аллергенов у детей с аутистическим спектром [17].

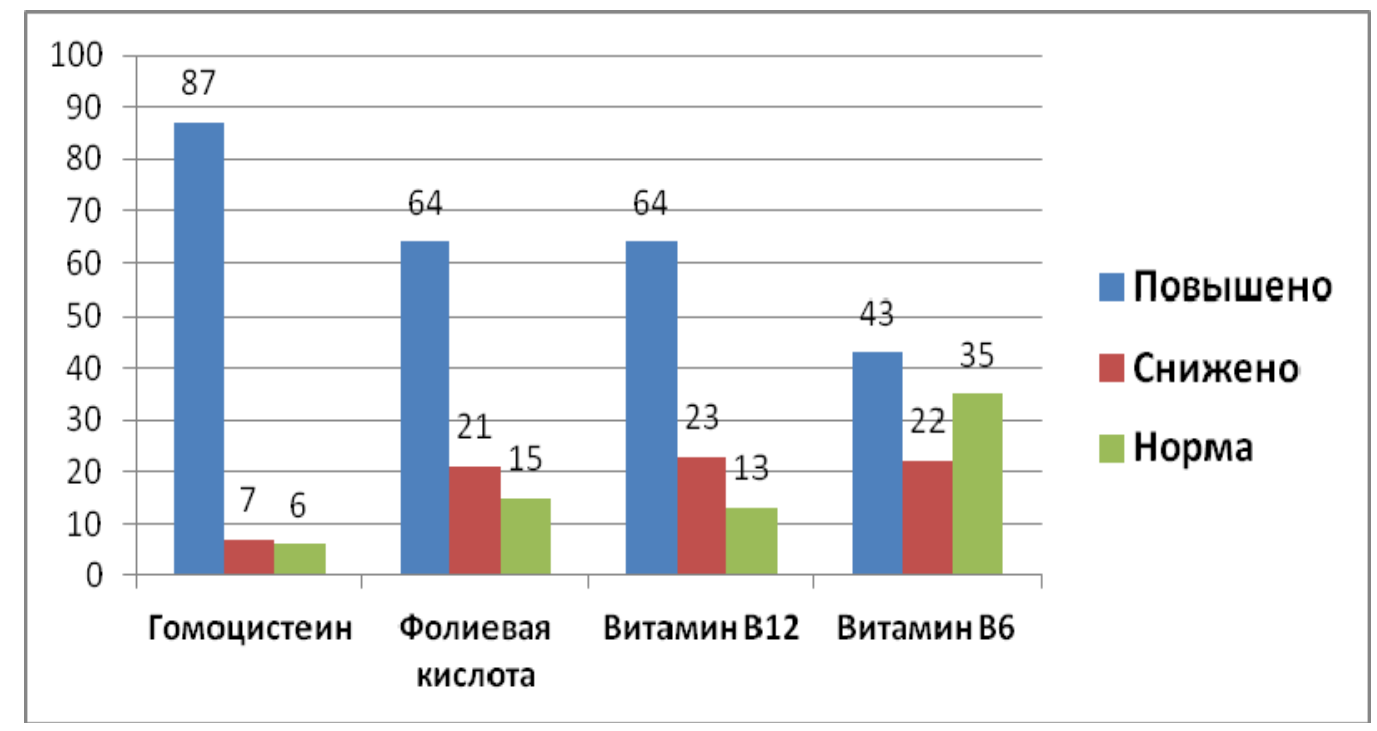

Рис. 2. Уровни сывороточных концентраций исследуемых биомаркеров среди детей с генетически детерминированным нарушением фолатного цикла $(\mathrm{n}=78)$

Дефицит NK- и NKT-клеток также объясняет частое развитие побочных эффектов после вакцинаций, особенно - при введении живой аттенуированной вакцины против кори, краснухи и эпидемического паротита. Указанная форма клеточного иммунодефицита отмечалась среди 
участников исследуемой группы в 91\% случаев, т.е. являлась специфическим признаком, в то время как среди здоровых детей контрольной группы признаки аналогичного иммунологического фенотипа имели место лишь в 27\% случаев, причем обычно отмечалось незначительное снижение количества клеток ( $\left.<<0,05 ; \mathrm{Z}<\mathrm{Z}_{0,05}\right)$. Помимо этого, гораздо реже среди детей с аутистическим спектром отмечались другие нарушения иммунного статуса: снижение количества CD8+ Т-лимфоцитов (23\%), CD4+ Т-клеток (12\%), CD19+ В-лимфоцитов (9\% случаев). Таким образом, только в 23\% случаев был тотальный дефицит всех основных противовирусных субпопуляций лимфоцитов: Т-киллеров, естественных киллеров и естественных киллерных Т-лимфоцитов, причем именно у таких детей отмечалась наибольшая вирусная нагрузка на момент вступления в исследование. Преимущественно имел место избирательный дефицит противовирусных клеток врожденного иммунитета, a количество $\mathrm{CD} 8+$ T-лимфоцитов нередко оказывалось компенсаторно повышенным, что способствовало некоторому уменьшению вирусной нагрузки на организм ребенка. Такую форму иммунодефицита можно было легко идентифицировать в общем анализе крови, зафиксировав аномально малое количество клеток с фенотипом больших гранулярных лимфоцитов. Только у каждого десятого участника исследуемой группы было тотальное снижение всех исследуемых субпопуляций лимфоцитов, что отражалось в виде лимфопении в общем анализе крови. Нарушения отмечались и в гуморальном звене иммунитета. Дисиммуноглобулинемия, включающая изолированные и комбинированные дефициты отдельных классов и субклассов иммуноглобулинов, выявлена в 43\% случаев, однако чаще всего была неглубокой и носила транзиторный характер. Гипоиммуноглобулинемия зарегистрирована лишь в 17\% случаев. Дефицит миелопероксидазы фагоцитов отмечался в 35\% случаев и комбинировался с нарушениями в других звеньях иммунитета в вариабельной манере (рис. 3).

На основании данных анализа иммунного статуса можно выделить основные иммунологические фенотипы у детей с генетически 
детерминированным дефицитом фолатного цикла. Основным иммунологическим фенотипом, который отмечался почти у всех детей исследуемой группы, был дефицит противовирусного звена врожденного иммунитета: дефицит NK- и/или NKT-клеток, причем в 62\% случаев отмечалось резкое снижение количества лимфоцитов обеих субпопуляций. Изолированные дефициты NK- и NKT-клеток отмечались редко - в 13\% и 16\% случаев соответственно, а тотальный дефицит противовирусных клеток врожденного и адаптивного иммунитета выявлялся лишь в 23\% случаев, т.е. реже, чем у каждого третьего ребенка (рис. 4).

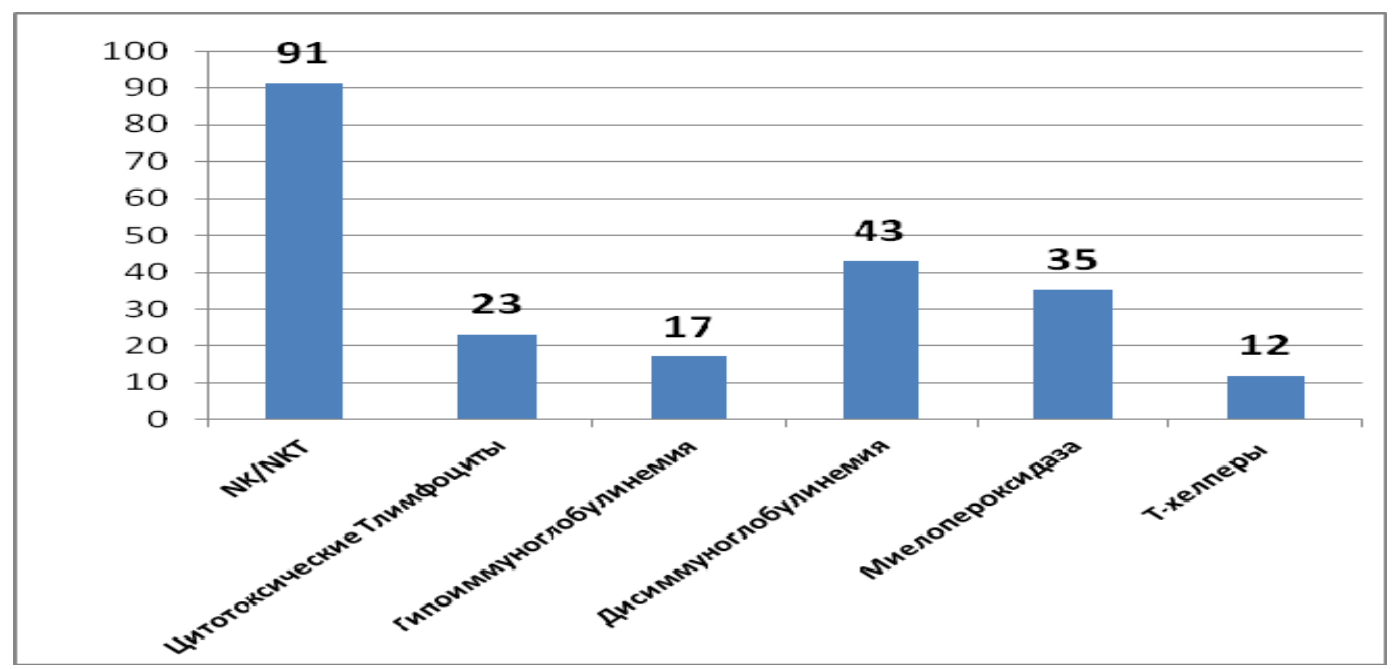

Рис. 3. Структура нарушений в иммунном статусе у детей с генетически детерминированным нарушением фолатного цикла $(\mathrm{n}=78)$

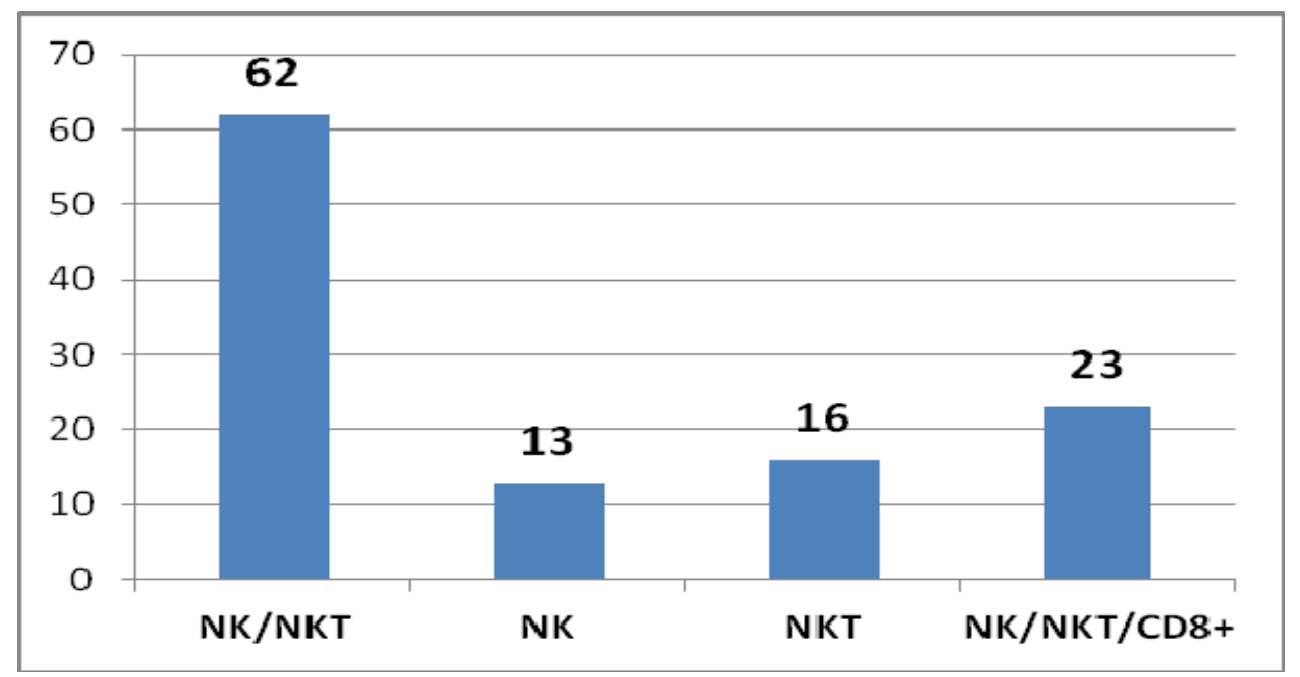

Рис. 4. Структура нарушений противирусного иммунитета у детей с генетическим дефицитом фолатного цикла $(\mathrm{n}=78)$ 
Дефициты NK и NKT-клеток были тесно ассоциированы с наличием полиморфизмов в генах ферментов фолатного цикла $(p=0,01)$, а также наблюдалась статистически значимая связь изучаемых генетических нарушений с дефицитом цитотоксических Т-лимфоцитов, экспрессирующих корецепторную молекулу CD8, и дефицитом микробицидного энзима фагоцитов миелопероксидазы ( $=0,05)$ (табл. 2).

Таблица 2.

Результаты расчета критерия хи-квадрат по отношению к показателям иммунного статуса при сравнении пациентов исследуемой $(\mathrm{n}=78)$ и контрольной $(\mathrm{n}=34)$ групп

\begin{tabular}{|c|c|c|}
\hline Дефицит клетки/фактора & $\chi^{2}$ & Статистическая значимость* \\
\hline NK и/или NКТ-клетки & 51,1 & $\mathrm{p}=0,01$ \\
\hline NK-клетки & 27,2 & $\mathrm{p}=0,01$ \\
\hline NKT-клетки & 23,1 & $\mathrm{p}=0,01$ \\
\hline CD8+ T-лимфоциты & 4,6 & $\mathrm{p}=0,05$ \\
\hline CD4+ T-лимфоциты & 2,7 & Статистически не значимо \\
\hline Миелопероксидаза & 4,4 & $\mathrm{p}=0,05$ \\
\hline IgM & 2,1 & Статистически не значимо \\
\hline IgG & 2,9 & Статистически не значимо \\
\hline IgA & 3,1 & Статистически не значимо \\
\hline IgЕ & 3,1 & Статистически не значимо \\
\hline Гипоиммуноглобулинения & 3,3 & Статистически не значимо \\
\hline Дисиммуноглобулинемия & 3,7 & Статистически не значимо \\
\hline
\end{tabular}

Примечание. * - $\chi^{2}=3,841$ при $p=0,05$ и 6,635 при $p=0,01$

Изолированный дефицит клеток-киллеров имел место в 19\% случаев, так как более, чем у половины участников исследуемой группы, отмечался расширенный иммунологический фенотип (54\%), при котором наряду с выраженным и стойким дефицитом NK- и NKT-клеток отмечались менее глубокие и преимущественно транзиторные нарушения в других звеньях иммунитета, а именно - дефицит CD8+ T-лимфоцитов, различные виды дисиммуноглобулинемии и дефицит миелопероксидазы фагоцитов. За счет подобных комбинаций могла видоизменяться клиническая картина инфекционного синдрома. Необходимо подчеркнуть, что в каждом десятом 
случае регистрировался фенотип, напоминающий тяжелый комбинированный иммунодефицит, за счет наслоения глубокой лимфопении и гипо- или дисиммуноглобулинемии. У таких детей отмечались эпизоды врожденной цитомегаловирусной инфекции с грубыми пороками развития нервной системы или постнатальные эпизоды вирусных энцефалитов с тяжелыми резидуальными симптомами. Это были дети, которым выставляли диагноз детского церебрального паралича, хотя при более глубоком анализе у них также обнаруживались признаки расстройств аутистического спектра. Как правило, в их геноме находилось сразу 4 полиморфизма генов фолатного цикла (рис. 5).

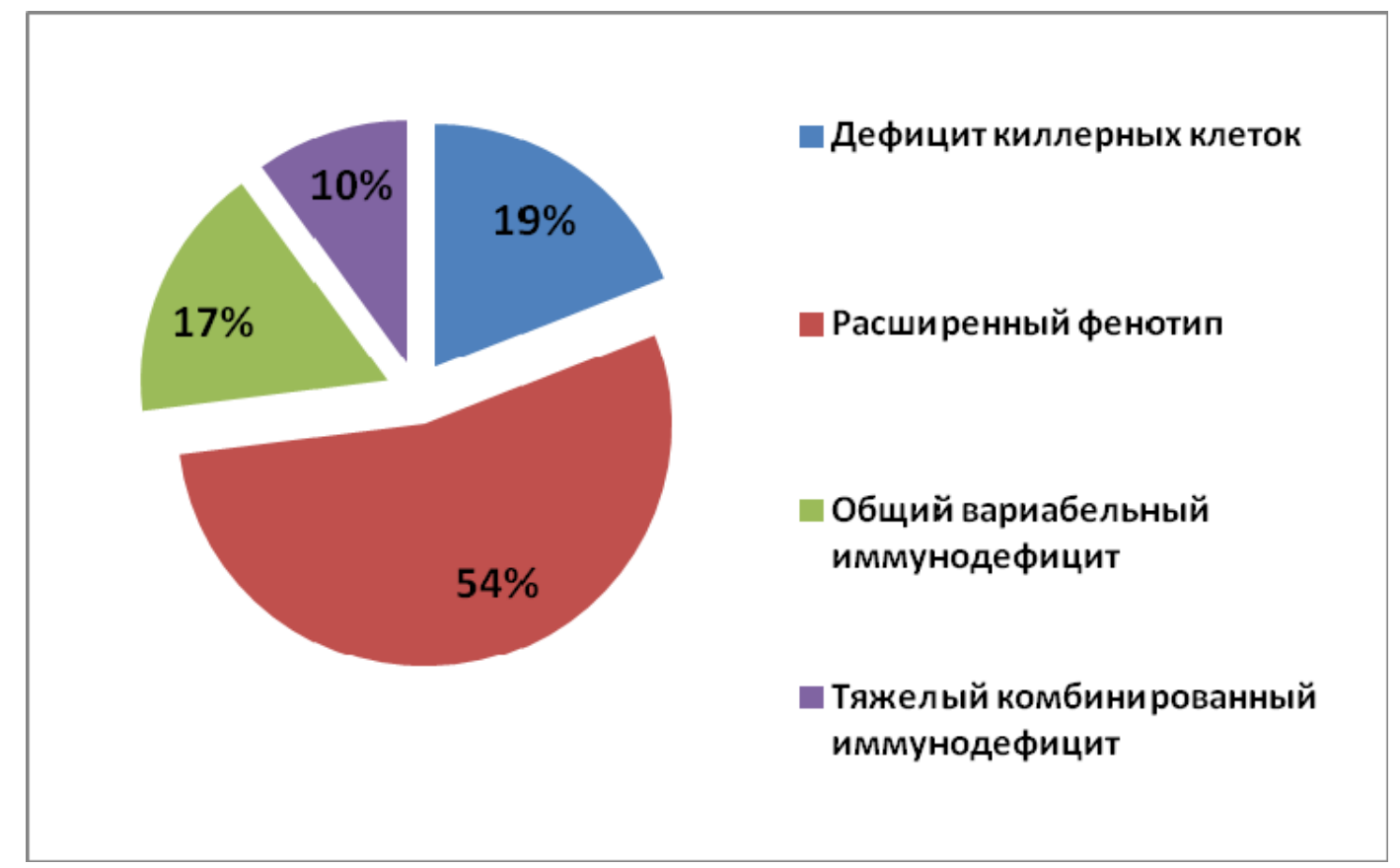

Рис. 5. Структура иммунологических фенотипов у детей с генетическим дефицитом фолатного цикла $(\mathrm{n}=78)$

Таким образом, генетический дефицит фолатного цикла приводит к развитию особой формы первичного иммунодефицита с вариабельным иммунологическим фенотипом, но преимущественным вовлечением NK- и NKT-клеток, что предопределяет резкое снижение резистентности к внутриклеточным микроорганизмам, опухолям и склонность к развитию аутоиммунных реакций и реакций гиперчувствительности замедленного 
типа. Мы предлагаем этот первичный иммунодефицит определять как «иммунодефицит, ассоциированный с генетическим нарушением фолатного цикла».

Выводы и перспективы дальнейших исследований. В клинической иммунологии описаны и изучены некоторые формы первичных иммунодефицитов, ассоциированные с расстройствами психики спектра аутизма у детей $[13,14]$. Анализ результатов наших исследований позволяет выделить новую форму первичного иммунодефицита - иммунодефицит, ассоциированный с генетическим нарушением фолатного цикла, наиболее типичным признаком которого является дефицит NK- и NKT-клеток как наиболее чувствительных к метаболическому дефекту, опосредованному полиморфизмами генов фолатного цикла. Данный иммунодефицит позволяет объяснить ключевые особенности клинико-лабораторного фенотипа многих детей с аутистическим спектром, для которого характерны аномальная микробная нагрузка, вызванная интрацеллюлярными патогенами [3, 10], разнообразные отклонения в иммунном статусе $[1,2,5,11,18]$, плохая переносимость вакцинаций, аномально высокая продукция антимозговых аутоантител [9, 17] и развитие реакций гиперчувствительности замедленного типа, например, к пищевым антигенам [8]. Иммунодефицит позволяет объединить в общий фенотип на первый взгляд разрозненные синдромы, которые часто последовательно развиваются у детей с аутистическим спектром, включая инфекционные поражения, лейкоэнцефалопатию, PANDAS, височную медианную эпилепсию и кишечные нарушения. Хотя, по-видимому, имеются и прямые метаболические воздействия энзимопатии, многие клинические проявления, отмечающиеся у детей с дефицитом фолатного цикла, связаны не с прямым токсическим воздействием гомоцистеина и других продуктов на нервные клетки, а с развитием иммунозависимых осложнений, опосредованных иммунодефицитом, включая нейроинфекционные поражения, аллергию, системное воспаление, 
поражение кишечника и индукцию аутоиммунных реакций к антигенам нервной ткани.

Следует указать, что с генетическим дефицитом фолатного цикла сегодня связывают и такие нарушения психики, как биполярное расстройство и шизофрения. Полученные нами данные позволяют предположить иммунозависимый компонент патогенеза в таких случаях.

\section{Список использованных источников}

1. Abe, I., Shirato, K., Hashizume, Y. (2013), "Folate-deficiency induced cellspecific changes in the distribution of lymphocytes and granulocytes in rats" Environ Health Prev. Med., vol. 18(1), pp. 78-84.

2. Bhatnagar, N., Wechalekar, A., McNamara, C. (2012), "Pancytopenia due to severe folate deficiency" Intern. Med. J., vol. 42(9), pp. 1063-1064.

3. Binstock, T. (2001), "Intra-monocyte pathogens delineate autism subgroups" Med. Hypotheses, vol. 56(4), pp. 523-531.

4. Borges, M.C., Hartwig, F.P., Oliveira, I.O., Horta, B.L. (2016) "Is there a causal role for homocysteine concentration in blood pressure? A Mendelian randomization study" Am. J. Clin. Nutr, vol. 103(1), pp. 39-49.

5. Courtemanche, C., Elson-Schwab, I., Mashiyama, S.T. (2004), "Folate deficiency inhibits the proliferation of primary human CD8+ T lymphocytes in vitro" J. Immunol., vol. 173(5), pp. 3186-3192.

6. DelGiudice-Asch, G., Simon, L., Schmeidler, J. (1999), "Brief report: a pilot open clinical trial of intravenous immunoglobulin in childhood autism" J. Autism Dev. Disord, vol. 29(2), pp. 157-160.

7. Frye, R.E. (2015), "Metabolic and mitochondrial disorders associated with epilepsy in children with autism spectrum disorder" Epilepsy Behav, vol. 47, pp. $147-157$.

8. Inaoka, M. (2005), "Innate immunity and hypersensitivity syndrome" Toxicology. vol. 209(2), pp. 161-163. 
9. Mora, M., Quintero, L., Cardenas, R. (2009) “Association between HSV-2 infection and serum anti-rat brain antibodies in patients with autism" Invest. Clin., vol. 50(3), pp. 315-326.

10. Nicolson, G.L., Gan, R., Nicolson, N.L., Haier J. (2007) "Evidence for Mycoplasma ssp., Chlamydia pneunomiae, and human herpes virus-6 coinfections in the blood of patients with autistic spectrum disorders" J. Neurosci Res, vol. 85(5), pp. 1143-1148.

11. Partearroyo, T., Úbeda, N., Montero, A. (2013), "Vitamin B(12) and folic acid imbalance modifies NK cytotoxicity, lymphocytes $B$ and lymphoprolipheration in aged rats" Nutrients. vol. 5(12), pp. 4836-4848.

12. Pu, D., Shen, Y., Wu, J. (2013), “Association between MTHFR gene polymorphisms and the risk of autism spectrum disorders: a meta-analysis" Autism Res, vol. 6(5), pp. 384-392.

13. Russo, A.J., Krigsman, A., Jepson, B., Wakefield, A. (2009), “Low serum myeloperoxidase in autistic children with gastrointestinal disease" Clinical and Experimental Gastroenterology, vol. 2, pp. 85-94.

14. Santaella, M.L., Varela, Y., Linares, N., Disdier, O.M. (2008), "Prevalence of autism spectrum disorders in relatives of patients with selective immunoglobulin A deficiency" P. R. Health. Sci J, vol. 27(3), pp. 204-208.

15. Schleinitz, N., Vély, F., Harlé, J.N., Vivier, E. (2010), "Natural killer cells in human autoimmune diseases" Immunology, vol. 131(4), pp. 451-458.

16. Schoendorfer, N.C., Obeid, R., Moxon-Lester, L. (2012), "Methylation capacity in children with severe cerebral palsy" Eur. J. Clin. Invest., vol. 42(7), pp. 768-776.

17. Singh, V.K., Lin, S.X., Yang, V.C. (1998), "Serological association of measles virus and human herpesvirus- 6 with brain autoantibodies in autism" Clin. Immunol. Immunopathol, vol. 89(1), pp. 105-108.

18. Troen, A.M., Mitchell, B., Sorensen, B. (2006), "Unmetabolized folic acid in plasma is associated with reduced natural killer cell cytotoxicity among postmenopausal women “ J. Nutr, vol. 136(1), pp. 189-194. 


\section{References}

1. Abe, I. Shirato, K. and Hashizume, Y. (2013), "Folate-deficiency induced cell-specific changes in the distribution of lymphocytes and granulocytes in rats", Environ Health Prev. Med., vol. 18(1), pp. 78-84.

2. Bhatnagar, N. Wechalekar, A. and McNamara, C. (2012), "Pancytopenia due to severe folate deficiency", Intern. Med. J., vol. 42(9), pp. 1063-1064.

3. Binstock, T. (2001), "Intra-monocyte pathogens delineate autism subgroups" Med. Hypotheses, vol. 56(4), pp. 523-531.

4. Borges, M. C. Hartwig, F. P. Oliveira, I. O. and Horta, B. L. (2016) "Is there a causal role for homocysteine concentration in blood pressure? A Mendelian randomization study", Am. J. Clin. Nutr, vol. 103(1), pp. 39-49.

5. Courtemanche, C. Elson-Schwab, I. Mashiyama, S. T. (2004), "Folate deficiency inhibits the proliferation of primary human CD8+ T lymphocytes in vitro", J. Immunol., vol. 173(5), pp. 3186-3192.

6. DelGiudice-Asch, G. Simon, L. and Schmeidler, J. (1999), "Brief report: a pilot open clinical trial of intravenous immunoglobulin in childhood autism", J. Autism Dev. Disord, vol. 29(2), pp. 157-160.

7. Frye, R. E. (2015), "Metabolic and mitochondrial disorders associated with epilepsy in children with autism spectrum disorder", Epilepsy Behav, vol. 47, pp. $147-157$.

8. Inaoka, M. (2005), "Innate immunity and hypersensitivity syndrome", Toxicology. vol. 209(2), pp. 161-163.

9. Mora, M. Quintero, L. Cardenas, R. (2009) "Association between HSV-2 infection and serum anti-rat brain antibodies in patients with autism", Invest. Clin., vol. 50(3), pp. 315-326.

10. Nicolson, G. L. Gan, R. Nicolson, N. L. and Haier, J. (2007) "Evidence for Mycoplasma ssp., Chlamydia pneunomiae, and human herpes virus-6 coinfections in the blood of patients with autistic spectrum disorders", J. Neurosci Res, vol. 85(5), pp. 1143-1148. 
11. Partearroyo, T. Úbeda, N. and Montero, A. (2013), "Vitamin B(12) and folic acid imbalance modifies NK cytotoxicity, lymphocytes B and lymphoprolipheration in aged rats", vol. 5(12), pp. 4836-4848.

12. Pu, D. Shen, Y. and Wu, J. (2013), “Association between MTHFR gene polymorphisms and the risk of autism spectrum disorders: a meta-analysis", Autism Res, vol. 6(5), pp. 384-392.

13. Russo, A. J. Krigsman, A. Jepson, B. and Wakefield, A. (2009), "Low serum myeloperoxidase in autistic children with gastrointestinal disease", Clinical and Experimental Gastroenterology, vol. 2, pp. 85-94.

14. Santaella, M. L. Varela, Y. Linares, N. Disdier, O. M. (2008), "Prevalence of autism spectrum disorders in relatives of patients with selective immunoglobulin A deficiency", P. R. Health. Sci J, vol. 27(3), pp. 204-208.

15. Schleinitz, N. Vély, F. Harlé, J. N. and Vivier, E. (2010), "Natural killer cells in human autoimmune diseases", Immunology, vol. 131(4), pp. 451-458.

16. Schoendorfer, N. C. Obeid, R. and Moxon-Lester, L. (2012), "Methylation capacity in children with severe cerebral palsy", Eur. J. Clin. Invest., vol. 42(7), pp. 768-776.

17. Singh, V. K. Lin, S. X. and Yang, V. C. (1998), "Serological association of measles virus and human herpesvirus-6 with brain autoantibodies in autism", Clin. Immunol. Immunopathol, vol. 89(1), pp. 105-108.

18. Troen, A. M. Mitchell, B. and Sorensen, B. (2006), "Unmetabolized folic acid in plasma is associated with reduced natural killer cell cytotoxicity among postmenopausal women", J. Nutr, vol. 136(1), pp. 189-194. 
